\title{
Out-of-Plane Vibration of Curved Uniform and Tapered Beams with Additional Mass
}

\author{
Hamdi Alper Özyiğit, ${ }^{1}$ Mehmet Yetmez, ${ }^{2}$ and Utku Uzun ${ }^{2}$ \\ ${ }^{1}$ Department of Mechatronics Engineering, Bulent Ecevit University, 67100 Zonguldak, Turkey \\ ${ }^{2}$ Department of Mechanical Engineering, Bulent Ecevit University, 67100 Zonguldak, Turkey \\ Correspondence should be addressed to Mehmet Yetmez; yetmez@beun.edu.tr
}

Received 4 May 2017; Revised 14 June 2017; Accepted 18 June 2017; Published 18 July 2017

Academic Editor: Edoardo Artioli

Copyright ( 2017 Hamdi Alper Özyiğit et al. This is an open access article distributed under the Creative Commons Attribution License, which permits unrestricted use, distribution, and reproduction in any medium, provided the original work is properly cited.

\begin{abstract}
As there is a gap in literature about out-of-plane vibrations of curved and variable cross-sectioned beams, the aim of this study is to analyze the free out-of-plane vibrations of curved beams which are symmetrically and nonsymmetrically tapered. Out-ofplane free vibration of curved uniform and tapered beams with additional mass is also investigated. Finite element method is used for all analyses. Curvature type is assumed to be circular. For the different boundary conditions, natural frequencies of both symmetrical and unsymmetrical tapered beams are given together with that of uniform tapered beam. Bending, torsional, and rotary inertia effects are considered with respect to no-shear effect. Variations of natural frequencies with additional mass and the mass location are examined. Results are given in tabular form. It is concluded that (i) for the uniform tapered beam there is a good agreement between the results of this study and that of literature and (ii) for the symmetrical curved tapered beam there is also a good agreement between the results of this study and that of a finite element model by using MSC.Marc. Results of out-of-plane free vibration of symmetrically tapered beams for specified boundary conditions are addressed.
\end{abstract}

\section{Introduction}

Due to their importance and wide using areas in engineering, dynamics of curved beams have been prevalently investigated by many researchers. Particularly, vibration analysis of curved beams has been a remarkable research area in mechanics due to its various applications. For the complicated problems of many architectural and structural implementations, curved beams with variable cross-sections are generally main parts, such that beams can be used not only in the design of rib, curved continuous bridge, and ship, but also in gear, pump, turbine and so on. Kawakami et al. [1] present an approximate method to study the analysis for the inplane and out-of-plane free vibration of horizontally curved beams with arbitrary shapes and variable cross-sections. It is stated that the characteristic equation for free vibration can be derived by applying the Green function, which is obtained as a discrete type solution of differential equations governing the flexural behavior of the curved beam under the action of a concentrated load. Krishnan and Suresh [2] investigate the effect of shear deformation and rotary inertia on natural and cross over frequencies of both curved uniform and nonuniform (varied cross-section) beams by using a simple cubic linear beam element. Results of free and forced in-plane vibrations of circular arches with variable crosssections are given by Tong et al. [3] using the Kirchhoff assumptions for thin beams and taking the neutral axis as inextensible. Huang et al. [4] take into consideration out-ofplane dynamics of beams with arbitrarily varying curvature and cross-section by dynamic stiffness matrix method. Viola et al. $[5,6]$ investigate the in-plane linear free vibrations of nonuniform circular arches with damaged configurations by using analytical and generalized differential quadrature (GDQ) methods. Tornabene et al. [7] apply GDQ to solve linear dynamics of the arch with different geometrical and boundary conditions. Viola et al. $[8,9]$ present a solution of free harmonic vibration problem of multistepped and multidamaged arches by using analytical and GDQ with domain decomposition technique (GDQE) methods. In-plane free vibration of circular arches is worked by $\mathrm{Liu}$ and $\mathrm{Wu}[10]$ using the generalized differential quadrature rule (GDQR). Arches with uniform, continuously varying, and stepped 
cross-sections are presented to illustrate the validity and accuracy of the GDQR. Karami and Malekzadeh [11] analyze in-plane free vibration of circular arches with varying crosssections by developing a differential quadrature method. A boundary element method is developed by Sapountzakis [12] for the nonuniform torsional vibration problem of doubly symmetric composite bars of arbitrary variable cross-section. Chen [13] uses the differential quadrature element method (DQEM) for in-plane vibration analysis models of arbitrarily curved beam structures. Tufekci and Dogruer [14] analyze free out-of-plane vibrations of a circular arch with uniform cross-section with respect to effects of transverse shear and rotary inertia due to the both flexural and torsional vibrations. Yang et al. [15] investigate free in-plane vibration of uniform and nonuniform curved beams with variable curvatures, including the effects of the axis extensibility, shear deformation, and rotary inertia by using extended-Hamilton principle. Shin et al. [16] solve the problem of vibration of a circular arch with variable cross-section using differential transformation and generalized differential quadrature. Similarly, on one hand, Malekzadeh et al. [17-19] present inplane free vibration of laminated/functionally graded circular arches according to the differential quadrature method. On the other hand, Malekzadeh et al. [20] investigate out-ofplane free vibration of functionally graded circular curved beams in thermal environment. Another work about functionally graded circular curved beams is held by Piovan et al. [21]. In order to obtain natural frequencies for "bare" and "loaded" curved beams for different end conditions, $\mathrm{Wu}$ et al. [22] present an effective approach for free in-plane vibration analysis of a curved beam with various arbitrary concentrated elements. Özyiğit and Işık [23] investigate in-plane vibration of curved beams with variable crosssections carrying additional mass to compute frequencies of symmetrical and nonsymmetrical tapered beams with different mass locations. $\mathrm{Ni}$ et al. [24] pay attention to in-plane and out-of-plane free vibration and stability of a curved rod in flow. Vibration suppression of curved beams is regarded by Rostam et al. [25]. The performance of two curved beam element models based on coupled polynomial displacement fields is taken into account by Ishaquddin et al. [26] for out-of-plane vibration of arches. The coupled polynomial interpolation fields are derived independently for Timoshenko and Euler-Bernoulli beam elements using the force-moment equilibrium equations. Lee and Jeong [27] consider flexural and torsional free vibrations of horizontally curved beams on Pasternak foundations.

Since out-of-plane vibrations of curved and variable cross-sectioned beams are not widely studied, the purpose of this work is to analyze the free out-of-plane vibrations of curved beams which are symmetrically and nonsymmetrically tapered. In this analysis, the linear free out-of-plane vibrations of uniform and variable cross-section beams are considered by finite element method (FEM). The curvature of beams is circular and the cross-sections are taken circular and rectangular. The natural frequency is computed for different boundary conditions. An additional mass on beam is also considered and its effects on natural frequencies are investigated.

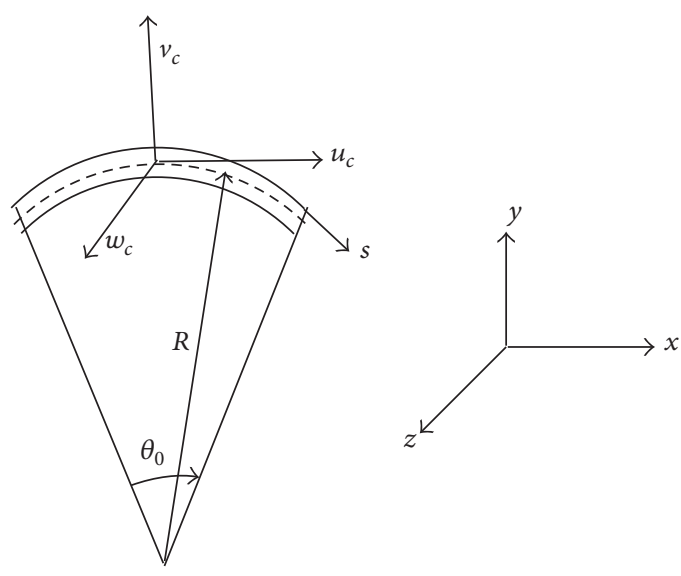

FIGURE 1: Curved beam element.

\section{Modeling and Governing Equations}

In applying finite element method to the approximate solution of curved beam problems, the following procedure can be considered [28-30]: Curved beam is modeled as a finite element as shown in Figure 1. $X, Y$, and $Z$ are global coordinates, and $u_{c}, v_{c}$, and $w_{c}$ are the tangential, radial, and out-of-plane displacements for the curved beam, respectively. Curved beam lies in $X-Y$ plane, $s$ is tangential coordinate, and $\theta_{0}$ is the arch angle of one finite element. The out-of-plane elastic and kinetic energy equations of the curved beam can be expressed as follows:

$$
\begin{aligned}
& U_{c}=\frac{1}{2} E I \int_{S} \kappa_{c}^{2} d s+\frac{1}{2} G J \int_{S} \varphi_{c}^{2} d s \\
& T_{c}=\frac{1}{2} \rho A \int_{S} \dot{w}_{c}^{2} d s+\frac{1}{2} \rho I \int_{S} \dot{\Psi}_{c}^{2} d s+\frac{1}{2} \rho J \int_{S} \dot{\Phi}_{c}^{2} d s,
\end{aligned}
$$

where $A$ is the cross-sectional area, $E$ is modulus of elasticity, $G$ is modulus of rigidity, and $I$ and $J$ are mass moment and polar moment of inertia, respectively. Due to the fact that the beam is assumed to be of Bernoulli-Euler type, shear effect on the beam is neglected. In (1), (.) denotes differentiation with respect to time $t$. Out-of-plane curvature change, torsion, and slope terms are

$$
\begin{aligned}
& \kappa_{c}=\frac{\Phi_{c}}{R}-\frac{\partial^{2} w_{c}}{\partial s^{2}}, \\
& \varphi_{c}=\frac{\partial \Phi_{c}}{\partial s}+\frac{1}{R} \frac{\partial w_{c}}{\partial s}, \\
& \Psi_{c}=\frac{\partial w_{c}}{\partial s},
\end{aligned}
$$

where $\Phi_{c}$ is the torsional displacement of the curved element. Out-of-plane displacement vector for one finite element is

$$
[V]_{c e}^{T}=\left[\begin{array}{llllll}
\Phi_{c i} & w_{c i} & \Psi_{c i} & \Phi_{c i+1} & w_{c i+1} & \Psi_{c i+1}
\end{array}\right] .
$$

Three degrees of freedom are taken for each node of elements. By following the finite element procedure, the stiffness and inertia matrices are obtained for out-of-plane vibrations. 
TABLE 1: Convergence analysis for the out-of-plane natural frequencies of the beam with midpoint mass location (see midpoint position as Position 1 in Table 11) under C-C end condition.

\begin{tabular}{lcccccccccc}
\hline \multirow{2}{*}{ Mode } & \multicolumn{9}{c}{ \# of elements } & \multicolumn{1}{c}{. } \\
& 10 & 20 & 30 & 40 & 50 & 60 & 70 & 80 & 90 & 100 \\
\hline 1 & 0.798 & 0.789 & 0.787 & 0.786 & 0.786 & 0.786 & 0.786 & 0.786 & 0.786 & 0.786 \\
2 & 6.076 & 6.015 & 6.003 & 6.000 & 5.997 & 5.996 & 5.995 & 5.995 & 5.995 & 5.994 \\
3 & 9.556 & 9.447 & 9.425 & 9.417 & 9.413 & 9.411 & 9.410 & 9.409 & 9.409 & 9.408 \\
4 & 21.190 & 20.977 & 20.937 & 20.923 & 20.917 & 20.913 & 20.911 & 20.910 & 20.909 & 20.908 \\
\hline
\end{tabular}

TABLE 2: Convergence analysis for the out-of-plane natural frequencies of the beam with bare position (see bare position as Position 6 in Table 11) under C-C end condition.

\begin{tabular}{lcccccccccc}
\hline \multirow{2}{*}{ Mode } & & \multicolumn{9}{c}{ \# of elements } \\
& 10 & 20 & 30 & 40 & 50 & 60 & 70 & 80 & 90 \\
\hline 1 & 2.220 & 2.197 & 2.193 & 2.191 & 2.190 & 2.190 & 2.190 & 2.190 & 2.189 & 2.189 \\
2 & 6.076 & 6.015 & 6.003 & 5.999 & 5.997 & 5.996 & 5.995 & 5.995 & 5.995 & 5.994 \\
3 & 12.436 & 12.307 & 12.282 & 12.273 & 12.269 & 12.267 & 12.266 & 12.265 & 12.264 & 12.264 \\
4 & 21.198 & 20.979 & 20.938 & 20.924 & 20.917 & 20.913 & 20.911 & 20.910 & 20.909 & 20.908 \\
\hline
\end{tabular}

TABLE 3: The out-of-plane nondimensional natural frequency parameters of uniform and circularly curved beams with circular cross-sections under $\mathrm{C}-\mathrm{C}$ end condition.

\begin{tabular}{|c|c|c|c|c|c|c|}
\hline $\bar{\theta}$ & Mode & Present study & Viola et al. [8] & Malekzadeh and Setoodeh [17] & Piovan et al. [21] & Ni et al. [24] \\
\hline \multirow{4}{*}{$60^{\circ}$} & 1 & 19.610 & 19.40190 & 19.398 & 19.442 & \\
\hline & 2 & 55.070 & 54.02958 & 54.014 & 54.093 & \\
\hline & 3 & 108.947 & 105.64828 & 105.61 & 105.707 & \\
\hline & 4 & 180.868 & 172.77355 & & & \\
\hline \multirow{4}{*}{$120^{\circ}$} & 1 & 4.490 & 4.451450 & 4.4515 & 4.471 & \\
\hline & 2 & 12.970 & 12.82629 & 12.825 & 12.885 & \\
\hline & 3 & 26.300 & 25.98937 & 25.984 & 26.064 & \\
\hline & 4 & 44.205 & 43.57053 & & & \\
\hline \multirow{4}{*}{$180^{\circ}$} & 1 & 1.8256 & 1.804340 & 1.8048 & 1.817 & 1.8108 \\
\hline & 2 & 5.2687 & 5.197995 & 5.1984 & 5.239 & 5.2359 \\
\hline & 3 & 11.0489 & 10.91819 & 10.918 & 10.984 & 11.0046 \\
\hline & 4 & 18.9317 & 18.72548 & & & 18.8837 \\
\hline
\end{tabular}

\section{Free Vibration Analysis: Results and Discussion}

Matrix equation for the free vibrations of the curved beam starts with an equation of the form

$$
[K]\{V\}+[M]\left\{\frac{d^{2} V}{d t^{2}}\right\}=\{0\},
$$

where $\{V\}$ is a global displacement vector and $[K]$ and $[M]$ are global stiffness and inertia matrices, respectively. The solution of (4) is assumed to be

$$
\{V\}=\{\bar{V}\} e^{j \omega_{n} t}
$$

where $j=\sqrt{-1}, \omega_{n}$ is natural frequency, and $\{\bar{V}\}$ is displacement amplitude vector of all nodes. Then, one can obtain the eigenvalue equation giving the natural frequencies for both in-plane and out-of-plane vibrations

$$
\left|[K]-\omega_{n}^{2}[M]\right|=0
$$

3.1. Convergence Study. A convergence study against the number of used elements is also put into consideration to see appropriate error reduction properties of the out-of-plane natural frequencies of the beam with or without mass under clamped end condition (C-C). Results of the convergence study are given in Tables 1 and 2 . It can be noted that the experimental convergence starts with 10 elements and ends up with 100 elements. The number of elements for optimal convergence is in the range of 90 and 100.

3.2. Uniform Beams. According to the finite element model proposed, vibration of uniform circularly curved beams is compared with that of the literature. Results of the outof-plane dimensionless frequencies of curved beams for clamped end condition (C-C) are given in Table 3. It can be noted that the results of the present study coincide with the results of the literature.

3.3. Curved Tapered Beams. Actually, many studies about inplane vibrations of curved tapered beams can be found in literature $[2,3,5-11,16-20]$. However, out-of-plane vibrations 
TABLE 4: Comparison of out-of-plane nondimensional fundamental natural frequency parameters of symmetrical tapered curved beams under $\mathrm{C}-\mathrm{C}$ end condition.

\begin{tabular}{|c|c|c|c|c|c|c|c|c|c|c|}
\hline \multirow{2}{*}{ Mode } & \multicolumn{2}{|c|}{$\alpha=0$} & \multicolumn{2}{|c|}{$\alpha=0.1$} & \multicolumn{2}{|c|}{$\alpha=0.2$} & \multicolumn{2}{|c|}{$\alpha=0.3$} & \multicolumn{2}{|c|}{$\alpha=0.4$} \\
\hline & FEM & Marc & FEM & Marc & FEM & Marc & FEM & Marc & FEM & Marc \\
\hline 1 & 1.82656 & 1.71268 & 1.99231 & 1.95735 & 2.16707 & 2.06221 & 2.37049 & 2.23698 & 2.55085 & 2.35337 \\
\hline 2 & 5.2687 & 4.96329 & 5.62739 & 5.29291 & 5.97692 & 5.94196 & 6.35269 & 6.15867 & 6.70673 & 6.5816 \\
\hline 3 & 11.0489 & 10.90525 & 11.63925 & 11.25478 & 12.23346 & 11.99578 & 12.85946 & 12.82765 & 13.44632 & 13.31699 \\
\hline 4 & 18.9317 & 18.73466 & 19.8881 & 19.60848 & 20.90173 & 20.62211 & 21.87971 & 21.42602 & 22.83602 & 22.57947 \\
\hline
\end{tabular}

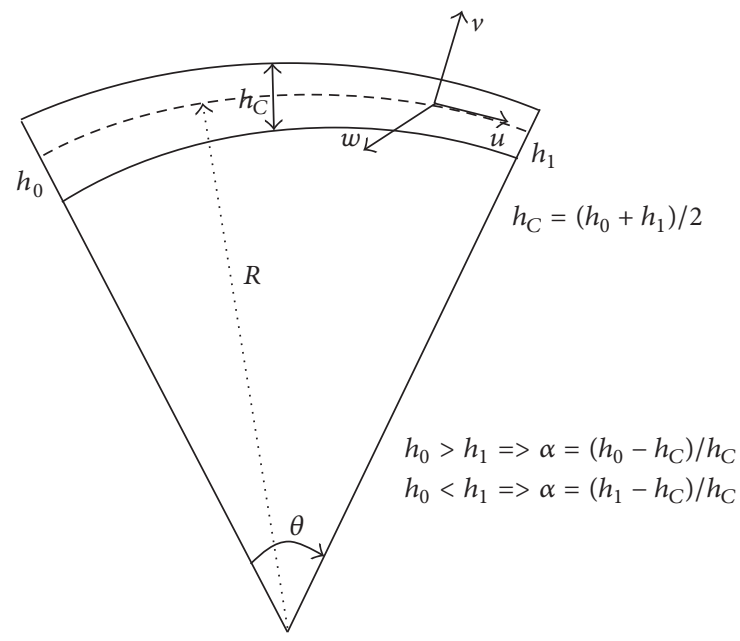

Figure 2: Unsymmetrical tapered beam.

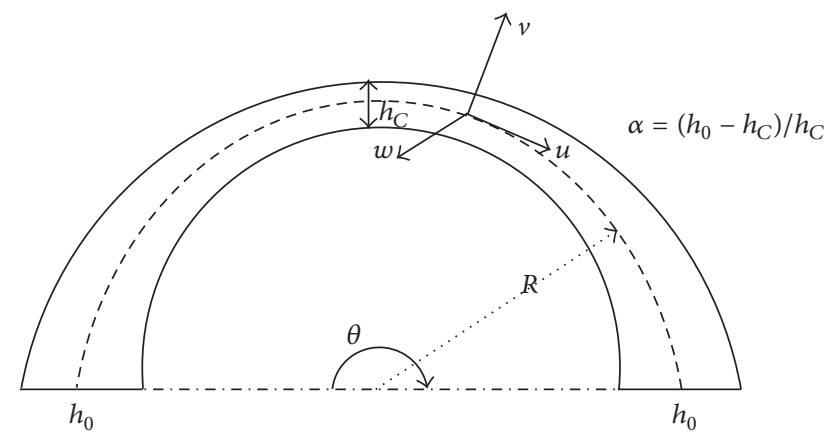

FIGURE 3: Symmetrical tapered beam.

of curved and variable cross-sectioned beams are not widely studied. The aim of this study is to analyze the free out-ofplane vibrations of curved beams which are symmetrically and nonsymmetrically tapered (see Figures 2 and 3 ).

It is assumed that (i) each beam possesses a constant width with $R$ as radius of the curvature, $\theta$ as arc angle, and $\alpha$ as cross-section change parameter and (ii) the beam is circularly curved and its cross-section is rectangular with height of the cross-section as $h_{0}$ at the beginning, $h_{c}$ at the crown, and $h_{1}$ at the end for an unsymmetrical tapered beam and as $h_{0}$ at both ends and $h_{c}$ at the crown for a symmetrical tapered beam.

For the comparison of out-of-plane nondimensional fundamental natural frequency parameters, symmetrical tapered curved beam analysis under C-C end condition (see Figure 3 ) is assumed to be under plane strain condition and the

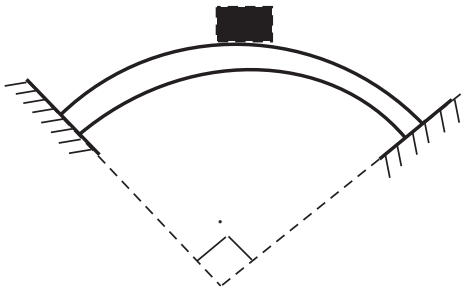

(a) $\mathrm{C}-\mathrm{C}$

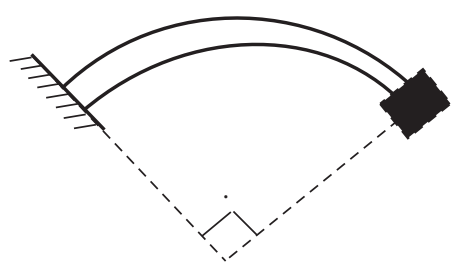

(b) C-F

FIGURE 4: Unsymmetrically tapered beams with additional mass.

general-purpose finite element code MSC.Marc (v2014, MSC Software, Santa Ana, CA, USA) is used. Four-node linear plane strain element (full integration 11) is considered for all five finite element beam models with constant 14400 elements, respectively. Results for the symmetrical curved tapered beam are given in Table 4. It is obvious that there is a good agreement between the results of this study and that of finite element model by MSC.Marc.

3.3.1. Unsymmetrical Tapered Beams. In the first part of this section, analysis of an unsymmetrical tapered beam or beam with varying cross-section, change of arc angle at different end conditions is considered. Cross-section change parameter is taken as 0.2 and 0.4 while $h_{c}$ is same for both $\left(h_{0}>h_{1}\right)$. First natural frequency parameters for clamped (C$\mathrm{C})$, clamped-hinged $(\mathrm{C}-\mathrm{H})$, and hinged $(\mathrm{H}-\mathrm{H})$ end conditions are shown in Table 5. It is noted that (i) frequencies decrease with increasing of arc angle, (ii) as expected, the frequencies decrease from $\mathrm{C}-\mathrm{C}$ to $\mathrm{H}-\mathrm{H}$ end conditions, and (iii) increase of $\alpha$ causes an increase for frequencies at $\mathrm{C}-\mathrm{H}$ and mostly a decrease at the other two end conditions.

In the second part of this section, an additional mass is considered on some points of tapered beams. Corresponding to $\mathrm{C}-\mathrm{C}$ boundary conditions and $90^{\circ}$ arc angle, a curved beam with a concentrated mass $(10 \mathrm{~kg})$ at the midpoint is given in Figure 4(a). In Figure 4(b), the same beam is under free right end $(\mathrm{C}-\mathrm{F})$ and mass location at the free end. Dimensionless 
TABLE 5: Nondimensional fundamental natural frequency parameters of unsymmetrical tapered curved beams.

\begin{tabular}{|c|c|c|c|c|c|c|}
\hline \multirow{2}{*}{$\theta$} & \multicolumn{2}{|c|}{ C-C } & \multicolumn{2}{|c|}{$\mathrm{C}-\mathrm{H}$} & \multicolumn{2}{|c|}{$\mathrm{H}-\mathrm{H}$} \\
\hline & $\alpha=0.2$ & $\alpha=0.4$ & $\alpha=0.2$ & $\alpha=0.4$ & $\alpha=0.2$ & $\alpha=0.4$ \\
\hline $30^{\circ}$ & 80.43 & 78.28 & 58.19 & 59.81 & 34.51 & 33.12 \\
\hline $60^{\circ}$ & 19.69 & 19.20 & 14.04 & 14.56 & 7.82 & 7.51 \\
\hline $90^{\circ}$ & 8.47 & 8.29 & 5.90 & 6.21 & 2.896 & 2.782 \\
\hline $120^{\circ}$ & 4.58 & 4.50 & 3.09 & 3.32 & 1.186 & 1.139 \\
\hline $150^{\circ}$ & 2.811 & 2.779 & 1.826 & 2.017 & 0.409 & 0.393 \\
\hline $180^{\circ}$ & 1.888 & 1.877 & 1.190 & 1.350 & 0.020 & 0.021 \\
\hline $270^{\circ}$ & 0.873 & 0.876 & 0.593 & 0.668 & 0.446 & 0.402 \\
\hline $360^{\circ}$ & 0.635 & 0.629 & 0.477 & 0.513 & 0.041 & 0.041 \\
\hline
\end{tabular}

TABLE 6: Nondimensional natural frequencies of unsymmetrical tapered curved beams with C-C end conditions.

\begin{tabular}{lcccccccc}
\hline \multirow{2}{*}{ Mode } & \multicolumn{2}{c}{$\alpha=0.1$} & \multicolumn{2}{c}{$\alpha=0.2$} & \multicolumn{2}{c}{$\alpha=0.3$} & \multicolumn{2}{c}{$\alpha=0.4$} \\
& Bare & Loaded & Bare & Loaded & Bare & Loaded $^{*}$ & Bare $^{\text {Loaded }^{*}}$ \\
\hline 1 & 8.51 & 4.76 & 8.47 & 4.75 & 8.40 & 4.74 & 8.29 & 4.72 \\
2 & 24.16 & 24.08 & 24.00 & 23.73 & 23.73 & 23.13 & 23.33 \\
3 & 48.04 & 38.59 & 47.73 & 38.78 & 47.17 & 39.05 & 46.34 & 39.34 \\
4 & 79.94 & 79.44 & 79.42 & 77.59 & 78.48 & 74.85 & 77.09 \\
\hline
\end{tabular}

${ }^{*}$ Loaded with additional mass $(10 \mathrm{~kg})$ at midpoint of the beam $\left(\theta=90^{\circ}\right)$.

TABLE 7: Nondimensional natural frequencies of unsymmetrical tapered curved beams with C-F end conditions.

\begin{tabular}{lcccccccc}
\hline \multirow{2}{*}{ Mode } & \multicolumn{2}{c}{$\alpha=0.1$} & \multicolumn{2}{c}{$\alpha=0.2$} & \multicolumn{2}{c}{$\alpha=0.3$} & \multicolumn{2}{c}{$\alpha=0.4$} \\
& Bare & Loaded $^{*}$ & Bare & Loaded $^{*}$ & Bare & Loaded $^{*}$ & Bare $^{\text {Loaded }^{*}}$ \\
\hline 1 & 1.84 & 0.87 & 2.04 & 0.92 & 2.25 & 0.97 & 2.48 & 1.00 \\
2 & 8.43 & 5.97 & 8.80 & 6.16 & 9.14 & 6.32 & 9.46 \\
3 & 24.28 & 19.77 & 24.56 & 19.85 & 24.74 & 19.82 & 24.81 & 19.44 \\
4 & 48.13 & 41.66 & 48.25 & 41.57 & 48.15 & 41.29 & 47.81 \\
\hline
\end{tabular}

${ }^{*}$ Loaded with additional mass $(10 \mathrm{~kg})$ at free end of the beam $\left(\theta=90^{\circ}\right)$.

natural frequency parameters of unsymmetrically tapered curved beams at C-C boundary conditions are presented in Table 6. The results represent both bare and mass loaded cases with the range of $\alpha$ as $0.1-0.4$ and constant $h_{c}$.

In the third part of this section, similar computation for $\mathrm{C}-\mathrm{F}$ beam with the additional mass at the free end is completed with respect to bare and loaded beam cases. Results of first four frequency parameters are shown in Table 7.

In the last part of this section, vibration for unsymmetrically tapered beams is considered for different arc angles. Again, according to bare and loaded beam cases, first natural frequencies are obtained for cross-section parameters 0.2 and 0.4 , respectively, as given in Table 8 .

3.3.2. Symmetrical Tapered Beams. Although there are number of studies about in-plane vibration of curved and symmetrically tapered beams in literature $[4,5,15]$, there is not any about out-of-plane vibration of that kind of structures. In this section, out-of-plane free vibration of symmetrically tapered beams at only C-C end conditions is put into consideration in such a way that (i) the beam is separated into 100 finite elements and (ii) a concentrated mass is located at
TABLe 8: Nondimensional fundamental natural frequencies of unsymmetrical tapered curved beams with C-F end condition (10 kg additional mass at the free end).

\begin{tabular}{lcccc}
\hline \multirow{\theta}{*}{} & \multicolumn{2}{c}{$\alpha=0.2$} & \multicolumn{2}{c}{$\alpha=0.4$} \\
\hline $30^{\circ}$ & Bare & Loaded & Bare & Loaded \\
$60^{\circ}$ & 16.41 & 7.167 & 20.21 & 7.529 \\
$90^{\circ}$ & 4.28 & 1.897 & 5.25 & 1.985 \\
$120^{\circ}$ & 2.04 & 0.925 & 2.48 & 0.961 \\
$150^{\circ}$ & 1.261 & 0.588 & 1.514 & 0.605 \\
$180^{\circ}$ & 0.906 & 0.435 & 1.071 & 0.442 \\
$270^{\circ}$ & 0.717 & 0.351 & 0.833 & 0.353 \\
$360^{\circ}$ & 0.481 & 0.226 & 0.533 & 0.226 \\
\hline
\end{tabular}

the midpoint. The beam, namely, a half circled curved beam $\left(\theta=180^{\circ}\right)$, is shown in Figure 5.

In the first part of this section, the fundamental natural frequencies for different arc angles' $\alpha$ values are obtained regarding bare and loaded cases. Results are presented in Table 9. One can clearly say that while increasing arc angle 
TABLE 9: Fundamental frequencies of symmetrical tapered beams under $\mathrm{C}-\mathrm{C}$ end condition.

\begin{tabular}{|c|c|c|c|c|c|c|c|c|}
\hline \multirow{2}{*}{$\theta$} & \multicolumn{2}{|c|}{$\alpha=0.1$} & \multicolumn{2}{|c|}{$\alpha=0.2$} & \multicolumn{2}{|c|}{$\alpha=0.3$} & \multicolumn{2}{|c|}{$\alpha=0.4$} \\
\hline & Bare & Loaded ${ }^{*}$ & Bare & Loaded* & Bare & Loaded ${ }^{*}$ & Bare & Loaded ${ }^{*}$ \\
\hline $20^{\circ}$ & 196.753 & 94.883 & 210.796 & 101.640 & 224.883 & 108.433 & 239.017 & 115.266 \\
\hline $40^{\circ}$ & 48.603 & 23.436 & 52.149 & 25.144 & 55.701 & 26.858 & 59.261 & 28.580 \\
\hline $60^{\circ}$ & 21.205 & 10.222 & 22.801 & 10.992 & 35.411 & 11.764 & 25.997 & 12.538 \\
\hline $80^{\circ}$ & 11.651 & 5.613 & 12.562 & 6.053 & 13.471 & 6.493 & 14.380 & 6.934 \\
\hline $100^{\circ}$ & 7.261 & 3.495 & 7.851 & 3.780 & 8.439 & 4.065 & 9.025 & 4.350 \\
\hline $120^{\circ}$ & 4.903 & 2.357 & 5.315 & 2.557 & 5.726 & 2.756 & 6.136 & 2.955 \\
\hline $140^{\circ}$ & 3.501 & 1.680 & 3.805 & 1.826 & 4.108 & 1.974 & 4.409 & 2.121 \\
\hline $160^{\circ}$ & 2.608 & 1.249 & 2.840 & 1.361 & 3.071 & 1.473 & 3.301 & 1.585 \\
\hline $180^{\circ}$ & 2.008 & 0.959 & 2.189 & 1.047 & 2.370 & 1.135 & 2.551 & 1.222 \\
\hline
\end{tabular}

${ }^{*}$ Loaded with additional mass $(50 \mathrm{~kg})$ at midpoint of the beam.

TABLE 10: Nondimensional out-of-plane natural frequencies of half circled uniform and symmetrical tapered beams $\left(\theta=180^{\circ}\right)$.

\begin{tabular}{|c|c|c|c|c|c|c|}
\hline \multirow{2}{*}{ Type } & \multirow{2}{*}{ Mode } & \multicolumn{5}{|c|}{ Amount of the additional mass } \\
\hline & & Bare & $25 \mathrm{~kg}$ & $50 \mathrm{~kg}$ & $75 \mathrm{~kg}$ & $100 \mathrm{~kg}$ \\
\hline \multirow{4}{*}{ Uniform } & 1 & 1.825 & 1.112 & 0.870 & 0.739 & 0.653 \\
\hline & 2 & 5.265 & 5.265 & 5.265 & 5.265 & 5.265 \\
\hline & 3 & 11.038 & 9.082 & 8.758 & 8.626 & 8.554 \\
\hline & 4 & 18.910 & 18.910 & 18.910 & 18.910 & 18.910 \\
\hline \multirow{4}{*}{$\begin{array}{l}\text { Tapered } \\
\alpha=0.3\end{array}$} & 1 & 2.370 & 1.449 & 1.135 & 0.963 & 0.851 \\
\hline & 2 & 6.353 & 6.353 & 6.353 & 6.353 & 6.353 \\
\hline & 3 & 12.860 & 10.457 & 10.066 & 9.908 & 9.822 \\
\hline & 4 & 21.880 & 21.880 & 21.880 & 21.880 & 21.880 \\
\hline
\end{tabular}

TABLE 11: The out-of-plane natural frequencies of the beam with different mass locations under C-C end condition.

\begin{tabular}{|c|c|c|c|c|c|c|}
\hline & Position 1 & Position 2 & Position 3 & Position 4 & Position 5 & Position 6 \\
\hline Mode & Midpoint (crown) & 40th-60th node & 30th-70th node & 20th-80th node & 10th-90th node & Bare \\
\hline 1 & 0.786 & 0.868 & 1.123 & 1.620 & 2.127 & 2.189 \\
\hline 2 & 5.994 & 2.921 & 2.342 & 2.870 & 4.948 & 5.994 \\
\hline 3 & 9.408 & 11.534 & 9.621 & 6.209 & 7.725 & 12.264 \\
\hline 4 & 20.908 & 14.013 & 20.491 & 14.923 & 11.729 & 20.908 \\
\hline
\end{tabular}

Additional mass: $100 \mathrm{~kg}, \alpha=0.2$.

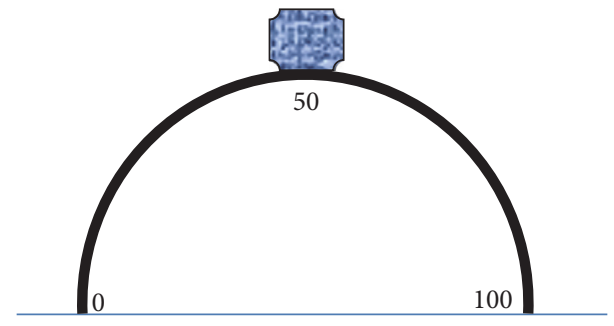

FIGURE 5: Symmetrically curved beam with additional mass is at the top (crown).

with additional mass decreases the frequencies, increasing of $\alpha$ with additional mass increases the frequencies.

In the second part of this section, again, the first five frequencies are computed for uniform and tapered $(\alpha=0.3)$ beams with the range of additional mass of $25-100 \mathrm{~kg}$. As seen in Table 10, results indicate that the significant point is about the even modes (2-4). On one hand, these two modes keep their constancy independently of the amount of the additional mass. On the other hand, odd modes show regular decreasing behavior due to the increasing of load.

In the last part of this section, a change of location of concentrated mass is taken into account under bare beam case. As represented in Table 11, the following conditions are considered: (i) mass is considered at midpoint as Position 1 $(100 \mathrm{~kg})$ and (ii) the mass is separated into two equal pieces (50 kg each) and these pieces are located at two sides symmetrically as Positions 2-5, respectively. For the first natural frequency point of view, it is said that increasing position number from 1 to 6 increases fundamental frequency. For the rest of the modes, there is an up-and-down behavior due to the locations of additional masses. Also, when comparing 
Positions 5 with 6 , first and second natural frequencies become close to each other.

\section{Conclusions}

Due to the fact that there is a gap in literature about outof-plane vibrations of curved and variable cross-sectioned beams, this study is presented to analyze the free out-ofplane vibrations of curved beams which are symmetrically and nonsymmetrically tapered. Results conclude that the finite element solution proposed here is suitable for vibration analyses of curved and tapered beams with or without additional mass.

\section{Conflicts of Interest}

The authors declare that they have no conflicts of interest.

\section{References}

[1] M. Kawakami, T. Sakiyama, H. Matsuda, and C. Morita, "Inplane and out-of-plane free vibrations of curved beams with variable sections," Journal of Sound and Vibration, vol. 187, no. 3, pp. 381-401, 1995.

[2] A. Krishnan and Y. J. Suresh, "A simple cubic linear element for static and free vibration analyses of curved beams," Computers and Structures, vol. 68, no. 5, pp. 473-489, 1998.

[3] X. Tong, N. Mrad, and B. Tabarrok, "In-plane vibration of circular arches with variable cross-sections," Journal of Sound and Vibration, vol. 212, no. 1, pp. 121-140, 1998.

[4] C. S. Huang, Y. P. Tseng, S. H. Chang, and C. L. Hung, "Out-ofplane dynamic analysis of beams with arbitrarily varying curvature and cross-section by dynamic stiffness matrix method," International Journal of Solids and Structures, vol. 37, no. 3, pp. 495-513, 2000.

[5] E. Viola and F. Tornabene, "Vibration analysis of damaged circular arches with varying cross-section," Structural Integrity \& Durability, vol. 1, pp. 155-169, 2005.

[6] E. Viola, E. Artioli, and M. Dilena, "Analytical and differential quadrature results for vibration analysis of damaged circular arches," Journal of Sound and Vibration, vol. 288, no. 4-5, pp. 887-906, 2005.

[7] F. Tornabene, R. Dimitri, and E. Viola, "Transient dynamic response of generally-shaped arches based on a GDQ-timestepping method," International Journal of Mechanical Sciences, vol. 114, pp. 277-314, 2016.

[8] E. Viola, M. Miniaci, N. Fantuzzi, and A. Marzani, "Vibration analysis of multi-stepped and multi-damaged parabolic arches using GDQ," Curved and Layered Structures, vol. 2, no. 1, 2014.

[9] E. Viola, M. Dilena, and F. Tornabene, "Analytical and numerical results for vibration analysis of multi-stepped and multidamaged circular arches," Journal of Sound and Vibration, vol. 299, no. 1-2, pp. 143-163, 2007.

[10] G. R. Liu and T. Y. Wu, "In-plane vibration analyses of circular arches by the generalized differential quadrature rule," International Journal of Mechanical Sciences, vol. 43, no. 11, pp. 2597-2611, 2001.

[11] G. Karami and P. Malekzadeh, "In-plane free vibration analysis of circular arches with varying cross-sections using differential quadrature method," Journal of Sound and Vibration, vol. 274, no. 3-5, pp. 777-799, 2004.
[12] E. J. Sapountzakis, "Torsional vibrations of composite bars of variable cross-section by BEM," Computer Methods in Applied Mechanics and Engineering, vol. 194, no. 18-20, pp. 2127-2145, 2005.

[13] C.-N. Chen, "DQEM analysis of in-plane vibration of curved beam structures," Advances in Engineering Software, vol. 36, no. 6, pp. 412-424, 2005.

[14] E. Tufekci and O. Y. Dogruer, "Out-of-plane free vibration of a circular arch with uniform cross-section: Exact solution," Journal of Sound and Vibration, vol. 291, no. 3-5, pp. 525-538, 2006.

[15] F. Yang, R. Sedaghati, and E. Esmailzadeh, "Free in-plane vibration of general curved beams using finite element method," Journal of Sound and Vibration, vol. 318, no. 4-5, pp. 850-867, 2008.

[16] Y.-J. Shin, K.-M. Kwon, and J.-H. Yun, "Vibration analysis of a circular arch with variable cross-section using differential transformation and generalized differential quadrature," Journal of Sound and Vibration, vol. 309, no. 1-2, pp. 9-19, 2008.

[17] P. Malekzadeh and A. R. Setoodeh, "DQM in-plane free vibration of laminated moderately thick circular deep arches," Advances in Engineering Software, vol. 40, no. 9, pp. 798-803, 2009.

[18] P. Malekzadeh, "Two-dimensional in-plane free vibrations of functionally graded circular arches with temperaturedependent properties," Composite Structures, vol. 91, no. 1, pp. 38-47, 2009.

[19] P. Malekzadeh, M. M. Atashi, and G. Karami, "In-plane free vibration of functionally graded circular arches with temperature-dependent properties under thermal environment," Journal of Sound and Vibration, vol. 326, no. 3-5, pp. 837851, 2009.

[20] P. Malekzadeh, M. R. G. Haghighi, and M. M. Atashi, "Outof-plane free vibration of functionally graded circular curved beams in thermal environment," Composite Structures, vol. 92, no. 2, pp. 541-552, 2010.

[21] M. T. Piovan, S. Domini, and J. M. Ramirez, "In-plane and outof-plane dynamics and buckling of functionally graded circular curved beams," Composite Structures, vol. 94, no. 11, pp. 31943206, 2012

[22] J. S. Wu, F. T. Lin, and H. J. Shaw, "Free in-plane vibration analysis of a curved beam (arch) with arbitrary various concentrated elements," Applied Mathematical Modelling. Simulation and Computation for Engineering and Environmental Systems, vol. 37, no. 14-15, pp. 7588-7610, 2013.

[23] H. A. Özyiğit and M. Işık, "In-plane vibrations of curved beams with variable cross-sections carrying additional mass," in Proceedings of the 11th international Conference on Vibration Problems, Lisbon, Portugal, September 2013.

[24] Q. Ni, M. Li, M. Tang, Y. Wang, Y. Luo, and L. Wang, "In-plane and out-of-plane free vibration and stability of a curved rod in flow," Journal of Fluids and Structures, vol. 49, pp. 667-686, 2014.

[25] M. R. Rostam, F. Javid, E. Esmailzadeh, and D. Younesian, "Vibration suppression of curved beams traversed by off-center moving loads," Journal of Sound and Vibration, vol. 352, Article ID 12477, pp. 1-15, 2015.

[26] M. Ishaquddin, P. Raveendranath, and J. N. Reddy, "Efficient coupled polynomial interpolation scheme for out-of-plane free vibration analysis of curved beams," Finite Elements in Analysis and Design, 2014. 
[27] J. K. Lee and S. Jeong, "Flexural and torsional free vibrations of horizontally curved beams on Pasternak foundations," Applied Mathematical Modelling, vol. 40, no. 3, pp. 2242-2256, 2016.

[28] R. Davis, R. D. Henshell, and G. B. Warburton, "Curved beam finite elements for coupled bending and torsional vibration," Earthquake Engineering \& Structural Dynamics, vol. 1, no. 2, pp. 165-175, 1972.

[29] B. L. Koziey and F. A. Mirza, "Consistent curved beam element," Computers and Structures, vol. 51, no. 6, pp. 643-654, 1994.

[30] P. Litewka and J. Rakowski, "An efficient curved beam finite element," International Journal for Numerical Methods in Engineering, vol. 40, no. 14, pp. 2629-2652, 1997. 


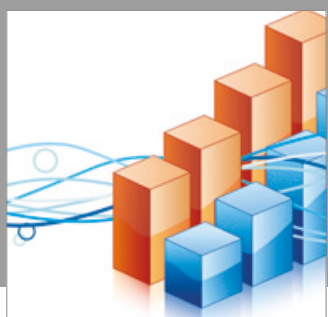

Advances in

Operations Research

vatersals

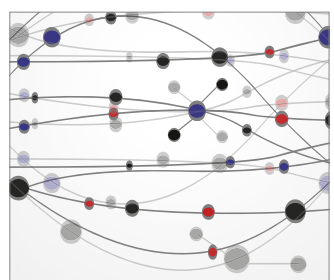

\section{The Scientific} World Journal
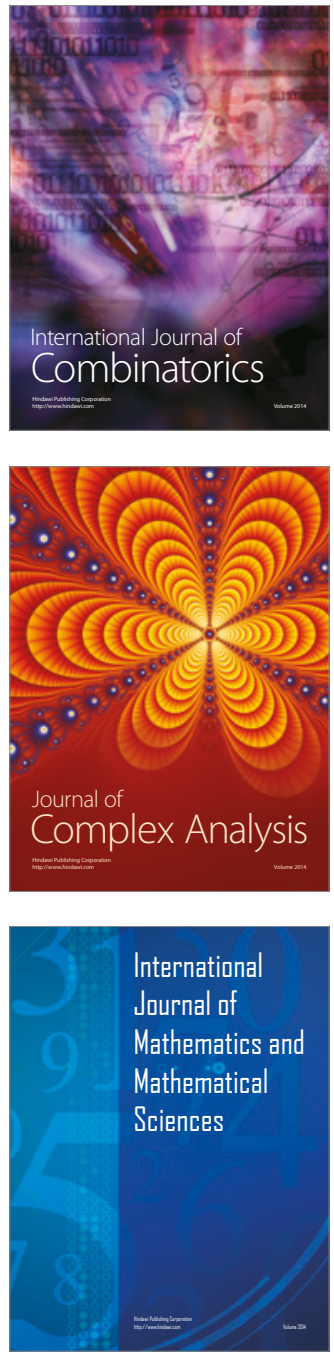
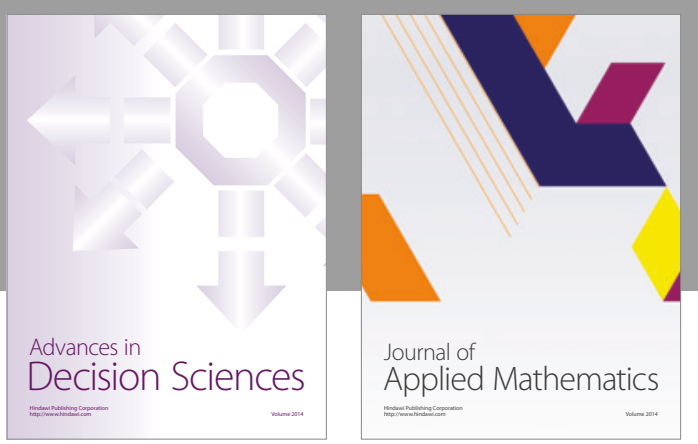

Algebra

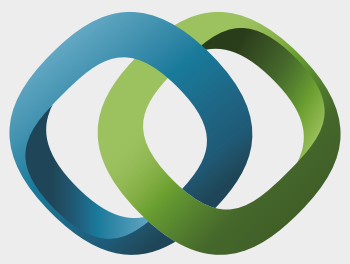

\section{Hindawi}

Submit your manuscripts at

https://www.hindawi.com
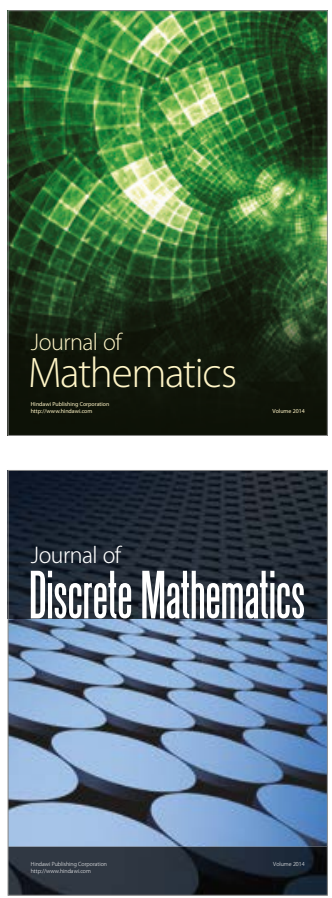

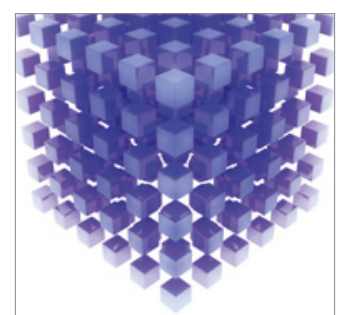

Mathematical Problems in Engineering
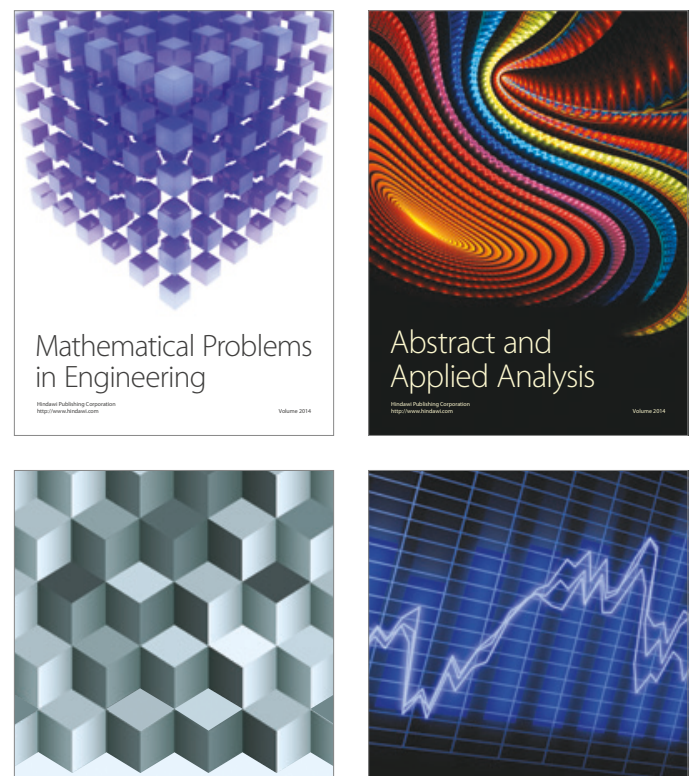

Journal of

Function Spaces

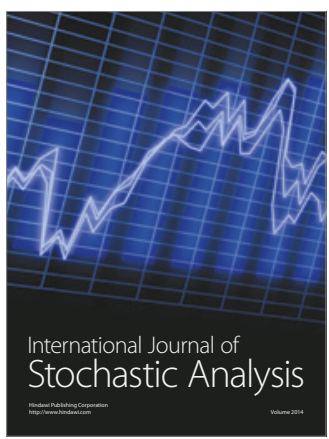

Probability and Statistics
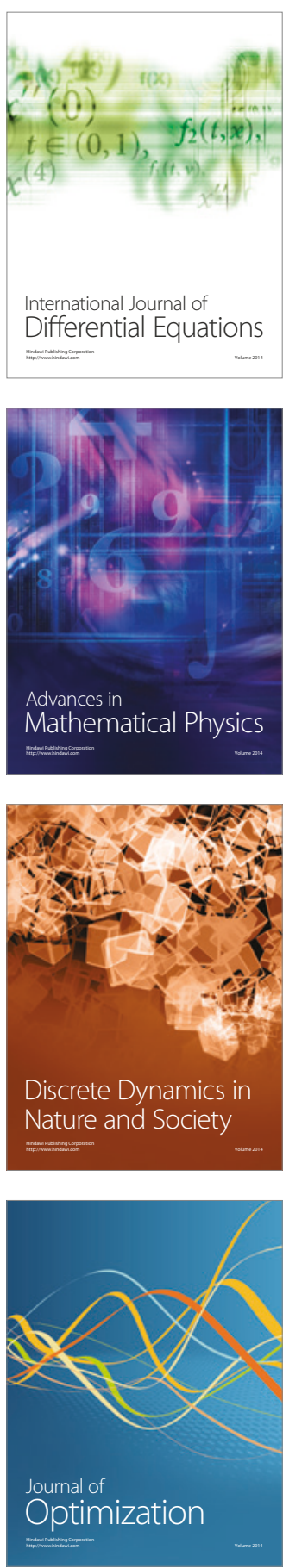